\title{
CXCL1-Chemokine (C-X-C Motif) Receptor 2 Signaling Stimulates the Recruitment of Bone Marrow-Derived Mesenchymal Cells into Diffuse-Type Gastric Cancer Stroma
}

Hiroaki Kasashima, ${ }^{*}$ Masakazu Yashiro, ${ }^{* \dagger}$ Hirohisa Nakamae, ${ }^{\ddagger}$ Kisyu Kitayama, ${ }^{*}$ Go Masuda, ${ }^{*}$ Haruhito Kinoshita, ${ }^{*}$ Tatsunari Fukuoka, ${ }^{*}$ Tsuyoshi Hasegawa, ${ }^{*}$ Takahiko Nakane, ${ }^{\ddagger}$ Masayuki Hino, ${ }^{\ddagger}$ Kosei Hirakawa, ${ }^{*}$ and Masaichi Ohira*

From the Departments of Surgical Oncology* and Hematology, ${ }^{\ddagger}$ and the Oncology Institute of Geriatrics and Medical Science, ${ }^{\dagger}$ Osaka City University Graduate School of Medicine, Osaka, Japan

Accepted for publication July 8, 2016.

Address correspondence to Masakazu Yashiro, M.D., Department of Surgical Oncology, Osaka City University Graduate School of Medicine, 1-4-3 Asahi-machi, Abeno-ku, Osaka 545-8585, Japan. E-mail: m9312510@ med.osaka-cu.ac.jp.

\begin{abstract}
Tumor stromal cells play a critical role in the progression of diffuse-type gastric cancer (DGC). The aim of this study was to clarify where tumor stromal cells originate from and which factor(s) recruits them into the tumor stroma. Immunodeficient mice with bone marrow transplantation from the cytomegalovirus enhancer/chicken $\beta$-actin promoter-enhanced green fluorescent protein mice were used for the in vivo experiments. An in vitro study analyzed the chemotaxis-stimulating factor from DGC cells using bone marrow-derived mesenchymal cells (BM-MCs). The influences of chemokine ( $C-X-C$ motif) receptor 2 (CXCR2) inhibitor on the migration of BM-MCs were examined both in vitro and in vivo. BM-MCs frequently migrated into stroma of DGC in vivo. The number of migrating BM-MCs was increased by conditioned medium from DGC cells. CXCL1 from DGC cells stimulated the chemoattractant ability of BM-MCs. Both antiCXCL1 antibody and CXCR2 inhibitor decreased the migration of BM-MCs, stimulated by DGC cells. A CXCR2 inhibitor, SB225002, reduced the recruitment of BM-MCs into the tumor microenvironment in vivo, decreasing tumor size and lymph node metastasis, and prolonging the survival of gastric tumor-bearing mice. These findings suggested that most tumor stromal cells in DGC might originate from BM-MCs. CXCL1 from DGC cells stimulates the recruitment of BM-MCs into tumor stroma via CXCR2 signaling of BM-MCs. Inhibition of BM-MC recruitment via the CXCL1-CXCR2 axis appears a promising therapy for DGC. (Am J Pathol 2016, 186: 3028-3039; http://dx.doi.org/10.1016/j.ajpath.2016.07.024)
\end{abstract}

Diffuse-type gastric cancer (DGC), diffusely infiltrating carcinoma, or Bormann type 4 (alias scirrhous gastric cancer) is characterized by extensive stromal fibrosis. The common features of DGC include rapid progression with frequent metastasis to lymph node and peritoneum ${ }^{1}$; therefore, DGC tends to have the high mortality of a 5-year survival rate from $10 \%$ to $15 \% .^{2-5}$ Various types of therapy, including chemotherapy, hormonal therapy, and irradiation, have been tested for DGC, but none have been satisfactory. $^{6-9}$ New therapies based on characteristic biological behaviors of DGC have been desired.

Activated fibroblasts in the tumor stroma, also termed cancer-associated fibroblasts (CAFs), play a critical role in the progression of cancer, ${ }^{10,11}$ particularly for
DGC, ${ }^{12-14}$ suggesting that CAFs might serve as novel therapeutic targets in the malignant progression of DGC. However, it remains unclear from where CAFs originate and by which factor(s) are CAFs induced. CAFs might preexist in the gastric tissue before tumor development, or they might be recruited to the tumor locus by cancer cell-originating signals. Our immunohistochemical study suggested that a large part of tumor stromal cells might be recruited from bone marrow into the gastric tumor

Supported in part by KAKENHI grants-in-aid for Scientific Research 23390329 (M.Y.) and 26293307 (K.H. and M.Y.) and by Osaka City University Priority Research Fund.

Disclosures: None declared. 
microenvironment. ${ }^{15}$ It would be effective cancer therapy to reduce the accumulation of bone marrow-derived mesenchymal cells (BM-MCs). Then, we analyzed the mechanisms responsible for the recruitment of BM-MCs into tumor stroma, and defined the efficacy of the inhibition of the recruitment of BM-MCs on the development of DGC. In this study, we found that BM-MCs recruit into tumor stroma of DGC and differentiate into CAFs. Taken together, we identified key signals, stimulating BM-MC homing capabilities into microenvironment of DGC. This is the first study to describe a novel targeted therapy for DGC by inhibition of the recruitment of BM-MCs into tumors.

\section{Materials and Methods}

\section{Cell Lines}

Gastric cancer cell lines, OCUM-2M, ${ }^{16}$ OCUM-2MLN cells, ${ }^{17}$ OCUM-2MD $3,{ }^{18}$ OCUM-12, ${ }^{19}$ KATO-III, ${ }^{20}$ and NUGC- $3,{ }^{21}$ were derived from DGC. SNU-16 and MKN-74 ${ }^{22}$ were derived from non-DGC. OCUM-2M, OCUM-2MLN cells, OCUM-2MD3, and OCUM-12 were established in our laboratory, and OCUM-2MD3 and OCUM-12 were authenticated by short tandem repeat profiling. KATO-III, NUGC-3, and MKN-74 were obtained from the JCRB Cell Bank (Osaka, Japan). SNU-16 was obtained from ATCC (Rockville, MD). After these cell lines were authenticated by short tandem repeat profiling before distribution to eliminate contamination, we cryopreserved them up to fifth passage. Cell lines were used in 3 months after thawing. We used four human gastric fibroblast cell lines, NF-37, NF-45, CaF-37, and CaF-45, which were derived from the gastric wall of DGC. CAFs were established from the tumoral gastric wall, and normal associated fibroblasts were from nontumoral gastric wall. ${ }^{23}$ The culture medium consisted of Dulbecco's modified Eagle's medium (DMEM; Nikken, Kyoto, Japan) with the addition of $10 \%$ fetal bovine serum (Nichirei, Tokyo, Japan), $100 \mathrm{IU} / \mathrm{mL}$ penicillin (Wako, Osaka, Japan), $100 \mathrm{mg} / \mathrm{mL}$ streptomycin (Wako), and $0.5 \mathrm{mmol} / \mathrm{L}$ sodium pyruvate (Wako). Cells were cultured at $37^{\circ} \mathrm{C}$ in $21 \% \mathrm{O}_{2}$.

\section{Isolation and Characterization of Human BM-MCs}

BM-MCs were obtained from bone marrow of the iliac crest of donors who underwent bone marrow puncture to examine hematological disorders. The bone marrow samples that were pathologically proved to be normal were cultured in a dish with MesenCult-XF Medium (STEMCELL Technologies, Grenoble, France). Adherent cells on dish were collected and transferred to another culture dish every 7 days. This study was approved by the Osaka City University ethics committee, and informed consent was obtained from patients before study. In culture medium, BM-MCs formed a monolayer of adherent cells and looked like long spindleshaped fibroblastic cells.

\section{Compound}

CXCL1, CXCL5, Dkk-1, lipocalin-2, CXCL8, chemokine (C-C motif) ligand 20 (CCL20), and EMMPRIN were purchased from R\&D Systems (Minneapolis, MN). A neutralizing antibody for CXCL1, anti-human CXCL1 antibody, was purchased from R\&D Systems. SB225002, a small synthetic molecule that interrupts $\mathrm{C}-\mathrm{X}-\mathrm{C}$ motif receptor 2 (CXCR2) pathways, was purchased from Abcam (Cambridge, MA). This compound shows considerable inhibitory activity against CXCR2. SB225002 was dissolved in $0.33 \%$ ethanol and $0.25 \%$ Tween-20, stored in a light-shielded container at $4^{\circ} \mathrm{C}$, and used within 3 days. For in vivo experiments, the agent dissolved in distilled water was administered by i.p. injection. For in vitro experiments, the diluted SB225002 was mixed at various concentrations with DMEM.

\section{Gastric Carcinoma Model}

In vivo experiments were performed on 4-week-old female athymic BALB/c nude mice (CLEA Japan, Tokyo, Japan). Bone marrow transplants were performed as described. ${ }^{24-26}$ Nude mice received a whole body sublethal irradiation and received an i.v. injection of $5 \times 10^{6}$ bone marrow cells collected from femurs and tibias of the cytomegalovirus enhancer/chicken $\beta$-actin promoter-enhanced green fluorescent protein (GFP) mice on the C57BL/6 background (Japan SLC, Hamamatsu, Japan). Mice with bone marrow transplantation were allowed to recover for 2 to 4 weeks, and orthotopic implantation of gastric cancer cells was performed to the mice as previously reported ${ }^{17,19}$ (Supplemental Figure S1). Under sevoflurane anesthesia, $1 \times 10^{7}$ OCUM$2 \mathrm{MLN}$ cells ${ }^{17}$ in a volume of $0.1 \mathrm{~mL}$ DMEM were inoculated into the gastric wall. We administered SB225002 $(1 \mathrm{mg} / \mathrm{kg} ; n=10)$ i.p. into mice once a day from the beginning of first day after the inoculation. Instead of SB225002, phosphate-buffered saline was used as the control. The mice were sacrificed 28 days after tumor inoculation, when the area and volume of gastric tumor, the number and weight of lymph node metastatic nodules, the weight of stomach, and the body weight were determined between the control group $(n=12)$ and the SB225002 group. The selected tissue sections were subjected to immunofluorescence study or immunohistochemical staining using antibodies against GFP (1:200; Life Technologies, Carlsbad, CA). Animal experiments were performed in compliance with the guidelines of the Osaka City University Ethical Committee.

\section{Proliferation Assay}

The effect of SB225002 on the proliferation of gastric cancer cell lines and BM-MCs was determined by Cell Counting Kit-8 (Dojindo, Kumamoto, Japan) assay. A total of $1 \times 10^{3}$ cancer cells or $1 \times 10^{4}$ BM-MCs were seeded into two 96-well plates with culture medium exposed to SB225002 at various concentrations (20 to $200 \mathrm{nmol} / \mathrm{L}$ ). 


\section{Quantitative Real-Time RT-PCR}

Real-time RT-PCR was performed using the ABI Prism 7000 (Applied Biosystems, Foster City, CA), as previously described. ${ }^{27}$ Total cellular RNA was extracted from cell lines with Trizol (Life Technologies). Relevant cDNA was amplified by PCR with Taq DNA polymerase (Nippon Gene, Tokyo, Japan) in a thermal cycler. Primer sets for CXCR2 (assay ID: Hs01891184) and for CTGF (assay ID: Hs01026927) were from Applied Biosystems. As an internal control, GAPDH (http://www.ncbi.nlm.nih.gov/nuccore; accession numbers NM_002046 and NM_001256799; probe, 5'-CCCCTGCAAATGAGCCCCAGCCTTC- ${ }^{\prime}$; forward, 5' CCATCTTCCAGGAGCGAGATC-3'; reverse, 5'-GGCAGAGATGATGACCCTTTTG-3') was purchased from Sigma-Aldrich (St. Louis, MO). RT-PCR was performed at $95^{\circ} \mathrm{C}$ for 15 seconds and $60^{\circ} \mathrm{C}$ for 60 seconds for 40 cycles.

\section{Flow Cytometry Analysis}

We wanted to examine the proportion of GFP-positive cells in bone marrow cells collected from femurs and tibias of transplanted nude mice. The percentage of positive cells was calculated and compared with bone marrow cells of nude mice without transplantation as control, using FACScan (BD LSR II; Becton Dickinson, San Diego, CA).

\section{CRISPR/Cas9-Mediated Genome Editing}

The single guide RNAs for CXCR2 and nontargeting control were purchased from Sigma-Aldrich. The target DNA sequences of the gRNAs used in this study are described in Supplemental Figure S2. A feature of this all-in-one vector (pLV-U6g-EPCG) is a Cas9 ORF flanked by puro and GFP elements, providing multiple options for monitoring stable cell populations that are expressing CRISPR components. A plasmid expressing Cas9-GFP was transiently transfected into BM-MCs with polybrene $(8 \mu \mathrm{g} / \mathrm{mL}) ; 48$ hours after transfection, puromycin $(1 \mu \mathrm{g} / \mathrm{mL})$ was added to the media. Total cellular RNA and protein were extracted from the transfected cells at 96 hours after transduction. RT-PCR and Western blotting were performed to check the deletion efficiency, and subsequently expanded for further analyses.

\section{Preparation of CM}

We prepared conditioned medium (CM) from gastric cancer cell lines and BM-MCs. To obtain CM, the plates were incubated for an additional 3 days in $3 \mathrm{~mL}$ serum-free DMEM. The supernatant was stored as $\mathrm{CM}$ at $-80^{\circ} \mathrm{C}$ until use. As a control, serum-free DMEM was used instead of CM.

\section{Wound-Healing Assay}

BM-MCs were cultured in 96-well plates (Essen ImageLock; Essen Instruments, Birmingham, UK). After the cells reached semiconfluence, a wound was generated in the cell monolayer with the 96-well WoundMaker (Essen BioScience Inc., Ann Arbor, MI). BM-MCs were cultured in DMEM with $5 \%$ fetal bovine serum and chemokines at each concentration. CXCL1, CXCL5, Dkk-1, lipocalin-2, CXCL8, CCL20, and EMMPRIN were diluted at the concentration of 200,10,100,100, 25, 1, and $5000 \mathrm{ng} / \mathrm{mL}$, respectively, with phosphate-buffered saline based on an inhibitory concentration of $50 \%$. Scratched fields were imaged every 1 hour, and monitored with Incucyte ZOOM Live-Cell Imaging System and software version 2015A (Essen Instruments).

\section{Chemotaxis Assay}

In vitro chemotaxis was measured by two-chamber assay using the chemotaxicell chambers (Millipore, Billerica, MA) with an $8-\mu \mathrm{m}$ pore membrane filter (upper chamber) in a 24-well culture plate (lower chamber), as previously reported. ${ }^{25} \mathrm{BM}-\mathrm{MCs}$ $\left(5 \times 10^{3}\right.$ cells $/ 250 \mu \mathrm{L} /$ chamber $)$ were seeded in the upper chamber, and $500 \mu \mathrm{L}$ of $\mathrm{CM}$ from gastric cancer cell lines or DMEM with chemokines at each concentration was added to the lower chamber. CXCL1, CXCL5, Dkk-1, lipocalin-2, CXCL8, CCL20, and EMMPRIN were diluted at the concentration of $200,10,100,100,25,1$, and $5000 \mathrm{ng} / \mathrm{mL}$, respectively, with phosphate-buffered saline. After incubation for 28 hours, BM-MCs that invaded through a filter to the lower surface of the membrane were stained by the Diff-Quik (Sysmex, Kobe, Japan), and were manually counted under a microscope at $\times 200$ magnification. Six randomly chosen fields were counted for each membrane, and the mean of six fields was calculated as the number of invaded BM-MCs.

\section{Proteome Profiler Protein Array}

Using the collected CM from cancer cells, a total of 102 cytokines were measured using Proteome Profiler Human XL Cytokine Array Kit (R\&D Systems), following the manufacturer's instruction (Supplemental Table S1). The chemiluminescence was detected by LAS-4000 mini (GE Healthcare, Pittsburgh, PA) and analyzed by Image Quant TL 7.0 (GE Healthcare).

\section{Enzyme-Linked Immunosorbent Assay}

Production of CXCL1 in each serum free-CM was quantified using an enzyme-linked immunosorbent assay kit (R\&D Systems), per the manufacturer's protocol. Briefly, $200 \mu \mathrm{L}$ of sample or standard in $200 \mu \mathrm{L}$ of GRO- $\alpha$ (CXCL1) was added to each well coated with each monoclonal antibody, and was incubated for 1 hour. After four washes, absorbance was measured on a microplate reader at $450 \mathrm{~nm}$.

\section{Immunofluorescence Microscopy}

To examine the localization of infiltrated GFP-positive BM-derived cells and $\alpha$-smooth muscle actin ( $\alpha$-SMA) 
expression in orthotopic tumor of nude mice, immunofluorescence microscopy was performed. The paraffin-blocked tissues were blocked with $3 \%$ bovine serum albumin (diluted in phosphate-buffered saline) for 30 minutes at room temperature. Orthotopic tumor was incubated with anti- $\alpha$-SMA antibody (1:100) and anti-GFP antibody (1:200) for 2 hours at room temperature, and secondary antibody incubation [Alexa Fluor 568, 1:400 (Abcam), Alexa Fluor 488, 1:400 (Abcam)] was performed for 2 hours at room temperature. Tissues were further incubated with DAPI (Wako; 1:1000) for 30 minutes at room temperature. Tissues were viewed under a fluorescence microscope, Leica Digital Microscopy DMI 6000 (Leica Microsystems, Heidelberg, Germany).

\section{Statistical Analysis}

The $\chi^{2}$ test or Fisher's exact test was used to determine the significance of differences between covariates. Survival durations were calculated with the Kaplan-Meier method and analyzed by the log-rank test to compare cumulative survival durations among patient groups. In addition, the Cox proportional hazards model was used to compute univariate hazards ratios for the study parameters. In all of the tests, $P<0.05$ was defined as statistically significant. In vitro, data are expressed as means $\pm \mathrm{SD}$ and significant difference was analyzed using the unpaired Student's $t$-test. Comparisons among data sets were made with the KruskalWallis one-way analysis of variance by ranks, followed by Student-Newman-Keuls multiple comparison test.

\section{Results}

\section{Bone Marrow Cells Recruit into Gastric Tumor Microenvironment}

Successful bone marrow transplantation was confirmed by fluorescence-activated cell sorter analysis (Supplemental Figure S3) of marrow cells of recipient mice 2 weeks after the transplantation of bone marrow from the cytomegalovirus enhancer/chicken $\beta$-actin promoter-enhanced GFP mice. Subsequently, the mice with bone marrow transplantation were used for the in vivo gastric tumor experiments. To clarify the contribution of BM-MCs in the gastric tumor microenvironment, the macroscopic and histopathological features of gastric tumors after the inoculation of OCUM-2MLN cells into mice were examined at several time points. Immunofluorescence microscopy shows that GFP-positive BM-MCs were present in the stroma of gastric tumors, and some GFPpositive cells were also positive for $\alpha$-SMA, a marker of myofibroblasts (Figure 1A). The number of BM-MCs was significantly much greater in the stroma of gastric tumors than in normal gastric tissue (Figure 1B). Because GFP fluorescence signal was decreased by paraffin-embedding treatment, the immunofluorescence intensity of GFP in BM-MCs was generally weak compared with the immunohistochemical image. We then used immunohistochemical analysis using an
anti-GFP antibody to detect GFP-positive BM-MCs. Figure $1 \mathrm{C}$ shows the representative images of gastric tumors after the orthotopic inoculation of OCUM-2MLN cells in nude mice with bone marrow transplants. The size of gastric tumor increased gradually. The tumor shows a histological scirrhous type of infiltrative cancer cells accompanied by stromal cells, which increased in a time-dependent manner. GFP staining by immunohistochemistry showed that a few GFP-positive BM-MCs were found in the tumor lesions 3 days after orthotopic inoculation. BM-MCs migrated around the arterial vessel in tumor tissue at 1 week after inoculation. At 2 to 4 weeks after inoculation, many BM-MCs gradually increased in the tumor microenvironment. Figure 1D shows the histopathological findings of gastric tumors using five gastric cancer cell lines, three DGC cell lines (OCUM-2MLN, OCUM-2MD3, and OCUM-12), and two non-DGC cell lines (MKN74 cells and SNU16). Gastric tumors, which developed after gastric inoculation of OCUM-2MLN cells, OCUM2MD3 cells, and OCUM-12 cells, showed a scirrhous-type growth of diffuse infiltration with extensive stromal cells. In contrast, gastric tumors originating from MKN74 cells and SNU16 cells proliferated in a medullary pattern with less stromal cells. Normal murine stomach consists of mucosa and tunica muscularis propria with a thin submucosal layer. Because tumor stromal cells with infiltrating BM-MCs were evident at 4 weeks, we performed the following in vivo experiments 4 weeks after inoculation to examine the effect of BM-MCs' migration and the consequent progression of gastric tumor.

\section{Diffuse-Type Gastric Cancer Cells Stimulate Migration Activity of BM-MCs}

Human BM-MCs were tested for spontaneous generation of both adipocytes and osteoblasts in vitro. Human BM-MCs were shown to have pluripotent capacity for chondrogenic, adipogenic, and osteogenic differentiation (Supplemental Figure S4). Figure 2A provides a representative phasecontrast image of BM-MCs that invaded into an 8 - $\mu \mathrm{m}$-pore membrane filter. The effect of tumor cell-derived CM on BM-MC migration was examined in a transwell migration assay. The number of migrating BM-MCs was significantly $(P<0.001)$ increased by CM from DGC cell lines, OCUM2MD3, OCUM-12, OCUM-2MLN, KATO-III, and NUGC3, but was not increased by that from non-DGC cell lines, MKN74 and SNU16 (Figure 2B). As shown in Figure 2, C and D, and Supplemental Figure S5, the protein array of the tumor CM indicated that many chemokines and cytokines were produced from gastric cancer cell lines. Protein signals on different arrays were compared between DGC cells and non-DGC cells. High levels of CXCL1, CXCL5, lipocalin-2, CXCL8, Dkk1, CCL20, and EMMPRIN were secreted by DGC cells, OCUM-2MD3, OCUM-12, OCUM-2MLN, KATO-III, and NUGC3 cells, but not by non-DGC cell lines, MKN74 or SNU16. To identify the factor(s) affecting the migration of BM-MCs, we performed a chemotaxis assay 
A Gastric tumor by OCUM-2MLN cells
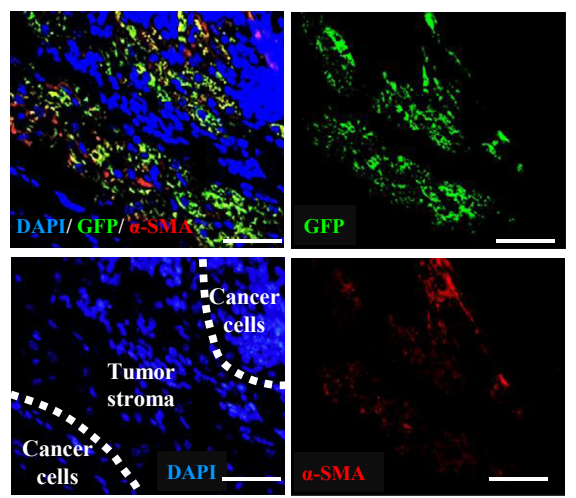

C

Time after gastric inoculation of OCUM-2MLN cells
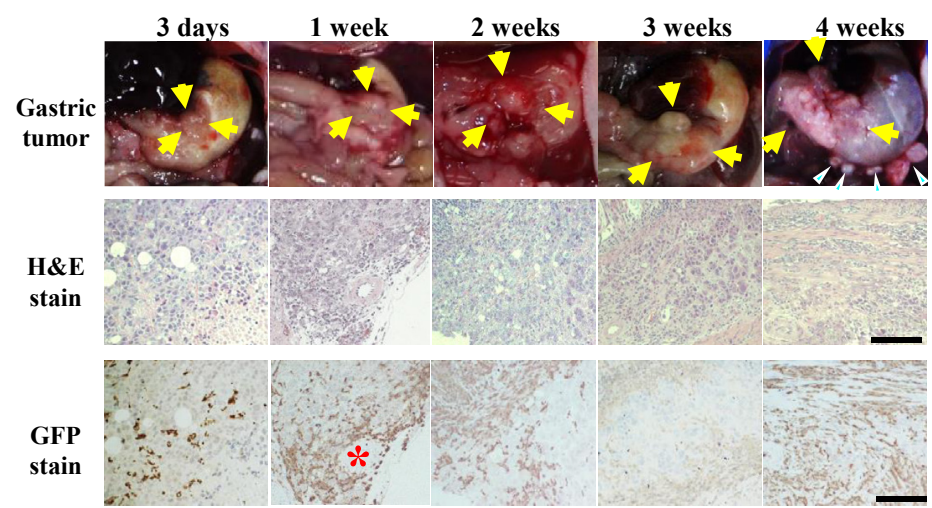

B

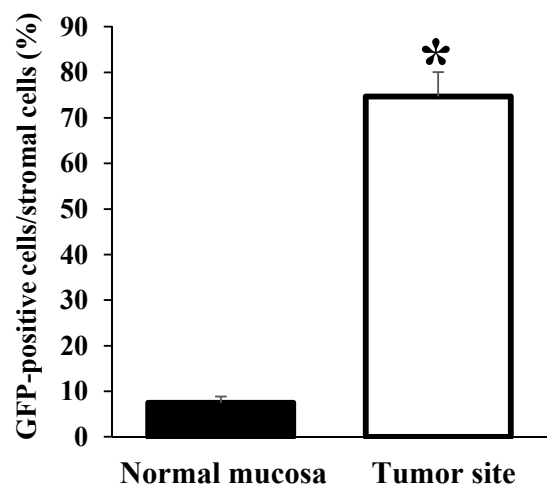

D
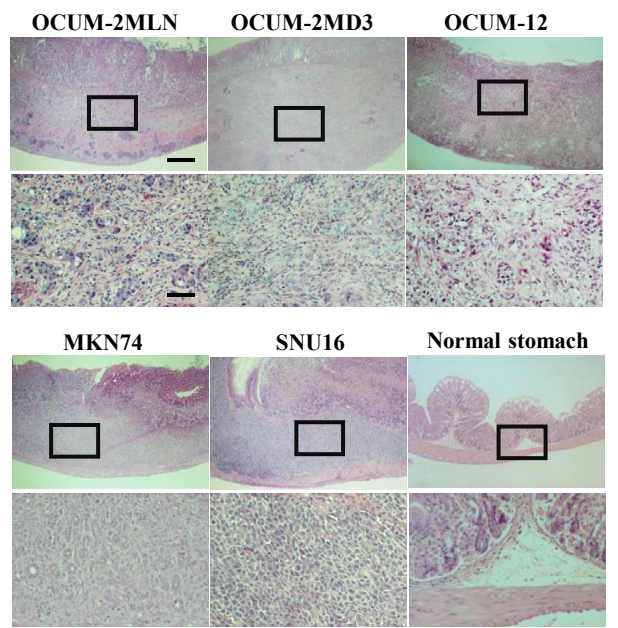

Figure 1 Macroscopic and histopathological features of gastric tumors after the orthotopic inoculation of gastric cancer cell lines into mice. A: Immunofluorescence of the gastric tumor formed by OCUM-2MLN cells in nude mice. Most stromal cells were positive for GFP (green) in the gastric tumor lesion, and some GFP-positive cells were stained with $\alpha$-SMA (red). In normal gastric tissue, the numbers of GFP-positive (green) BM-MCs were few. Cell nuclei were stained with DAPI (blue). B: Quantitation of bone marrow-derived cells in gastric tumor. Six randomly chosen fields were counted for each tumor site, and the mean of six fields was calculated. GFP-positive bone marrow-derived cells were significantly localized around tumor sites more than normal mucosa. C: Time course of gastric tumors after the inoculation of OCUM-2MLN cells in nude mice. The size of the gastric tumor (arrows) grew in a time-dependent manner. Three days after orthotopic inoculation, the tumor size was small and few GFP-positive BM-MCs were found in the tumor lesions. One week after inoculation, GFP-positive BM-MCs were frequently observed around the vessel (red asterisk). At 2 to 4 weeks after inoculation, gastric tumors showed extensive fibrosis with the occasional presence of poorly differentiated adenocarcinoma cells. Most stromal cells were GFP-positive BM-MCs. At 4 weeks after inoculation, multiple involved lymph nodes (arrowheads) were observed around the stomach. D: Histologic findings of gastric tumors by five gastric cancer cell lines. The gastric tumors produced by OCUM-2MLN cells, OCUM-2MD3 cells, and OCUM-12 cells showed infiltrative growth with extensive stromal cells, whereas those produced by SNU16 cells and MKN74 cells showed medullary growth with few stromal cells. The normal stomach consists of mucosa and tunica muscularis propria with a thin submucosal layer in nude mice. Boxed areas in the top rows are shown at higher magnification in the bottom rows. ${ }^{\star} P<0.05$. Scale bars: $50 \mu \mathrm{m}$ (A and $\mathbf{C}) ; 500 \mu \mathrm{m}$ (D, top rows); $100 \mu \mathrm{m}$ (D, bottom rows). H\&E, hematoxylin and eosin.

(Figure 3A) and a wound-healing assay (Figure 3B). Because CXCL1 stimulated the migration capacity of BM-MCs, we investigated whether this cytokine was associated with the migration-stimulating activity of CM from DGC cells. The CXCR2, a receptor of CXCL1, is expressed in stromal cells and related to tumor-stromal interactions in pancreatic cancer. ${ }^{28}$ The migration-stimulating activity was significantly $(P<0.05)$ decreased by anti-CXCL1 antibody (Figure 3C). Furthermore, we performed a CRISPR/Cas9-mediated genome editing to examine the effect of CXCR2 on the migration activity of BM-MCs. The transfection of $D G C X C R 2$ to BM-MCs successfully decreased the expression of $C X C R 2$ mRNA (Figure 3D) and protein (Figure 3E), and DGCXCR2 transfection significantly $(P<0.05)$ decreased the migration activity of BM-MCs (Figure 3F). In addition, CXCL1 was secreted at high levels $(>1500 \mathrm{pg} / \mathrm{mL}$ ) from DGC cells, whereas CXCL1 was undetectable $(<30 \mathrm{pg} / \mathrm{mL})$ in non-DGC cells (Figure $3 \mathrm{G})$.

Effect of CXCR2 Inhibitor, SB225002, on Gastric Tumor Progression in Nude Mice

SB225002 administration significantly $(P=0.039)$ prolonged the survival of mice $(n=10)$ with DGC by the 
A

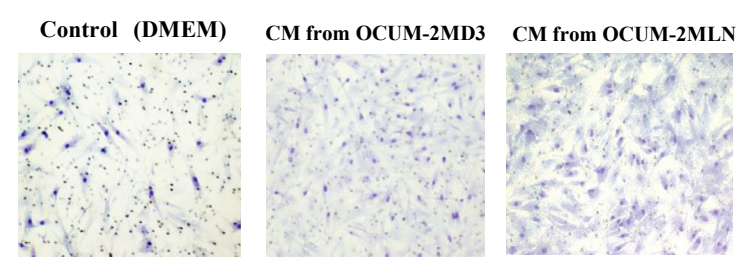

B

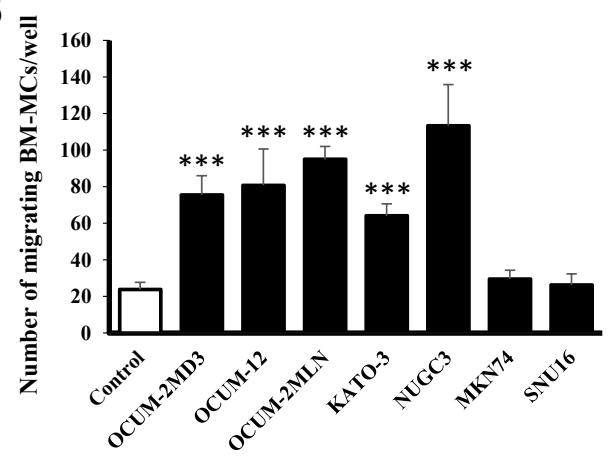

Conditioned medium from gastric cancer cells
C

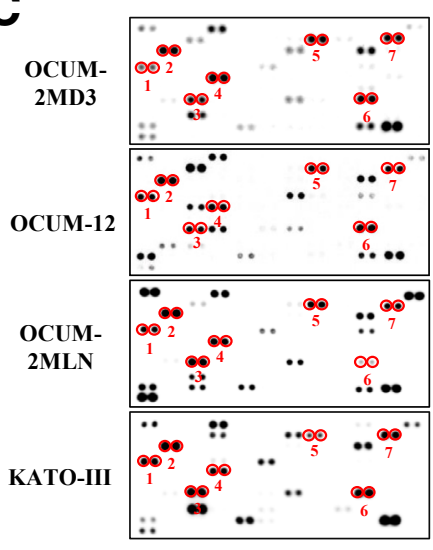

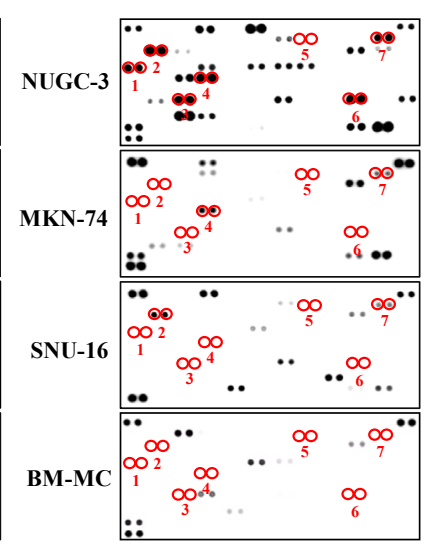

D

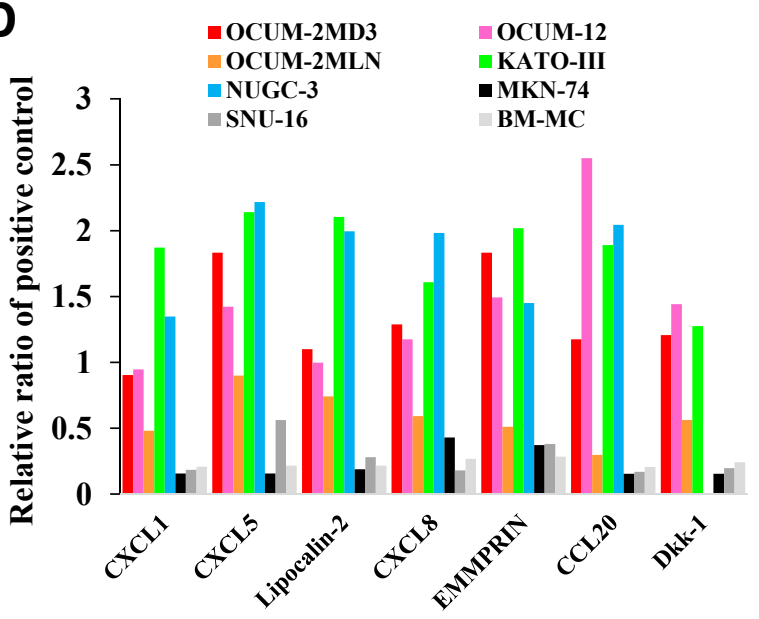

Figure 2 The effect of conditioned medium (CM) from gastric cancer cells on the migration activity of BM-MCs. A: Representative image of migrating BM-MCs into an 8- $\mu \mathrm{m}$-pore membrane filter. B: CM from DGC cell lines, OCUM-2MD3, OCUM-12, OCUM-2MLN, KATO-III, NUGC3, and NUGC4, significantly increased the number of migrating BM-MCs, but the non-DGC cell lines MKN74 and SNU16 had no effect. Six randomly chosen fields were counted for each assay, and the mean of six fields was calculated as the sample value. C: Profiles of cytokines in conditioned medium from culture cells. Antibodies of 102 cytokines were spotted on nitrocellulose membranes. CXCL1 (1), CXCL5 (2), lipocalin-2 (3), CXCL8 (4), Dkk1 (5), CCL-20 (6), and EMMPRIN (7) were commonly detected in DGC cell lines, OCUM-2MD3, OCUM-12, OCUM-2MLN, KATO-III, and NUGC3, but not in the non-DGC cell lines MKN74 and SNU16. D: Relative ratio of positive control of above seven cytokines by semiquantitative analysis. Consistent with the qualitative result, the above seven cytokines were more expressed in DGC cell lines than in non-DGC cell lines. $n=4$ (B). ${ }^{* *} P<0.001$ versus control. Original magnification: $\times 200$ (A). CCL, chemokine (C-C motif) ligand; DMEM, Dulbecco's modified Eagle's medium.

inoculation of OCUM-2MLN cells compared with that of vehicle mice $(n=16)$ (Figure 4A). At day 28 after inoculation of the OCUM-2MLN cells, surviving mice were sacrificed and gastric tumors were evaluated both macroscopically and microscopically. Figure 4B shows a representative image of a gastric tumor in mice with $(n=7)$ or without $(n=4)$ SB225002 administration. SB225002 significantly $(P<0.01)$ decreased the size of gastric tumors $\left(17.8 \mathrm{~mm}^{2}\right.$ versus $\left.84.5 \mathrm{~mm}^{2}\right)$ and the number of lymph node metastases (7.4 versus 2.5) in mice with SB225002 treatment $(n=7)$ in comparison with control mice $(n=4)$. In contrast, the body weight ( $19.1 \mathrm{~g}$ versus $21.4 \mathrm{~g}$ ) of mice was not different between the vehicle group and the SB225002 group (Figure 4C and Supplemental Table S2). Microscopically, the vehicle gastric tumor showed diffuse infiltration of cancer cells with abundant fibrous stromal cells with GFP expression in a time-dependent manner, whereas few stromal cells without GFP expression were found, as portrayed in Figure 1B. These findings suggest that the number of BM-MCs was much greater than that of preexisting stromal cells in the microenvironment of DGC. In contrast, the gastric tumors of mice treated with SB225002 administration showed medullary growth of cancer cells with scanty stromal cells at each week. Moreover, in the tumor treated by SB225002, necrotic lesions were evident and GFP-positive BM-MCs were sparse at each week after inoculation (Figure 4D). Immunofluorescence microscopy also revealed that abundant GFP-positive and $\alpha$-SMApositive bone marrow-derived myofibroblasts existed in the tumor stroma of vehicle mice. On the other hand, administration of SB225002 decreased BM myofibroblasts in tumor stroma (Figure 4E). Expression levels of Ki-67 in cancer cells were significantly $(P<0.01)$ decreased by SB225002 compared with the vehicle mice (Figure 5A). Although both gastric cancer cells and BM-MCs expressed CXCR2, with the expression levels of CXCR2 mRNA ranging from 0.41 (OCUM-2MLN) to 6.99 (NUGC-3) and those of BM-MC\#1 and BM-MC\#2 ranging between 1.30 

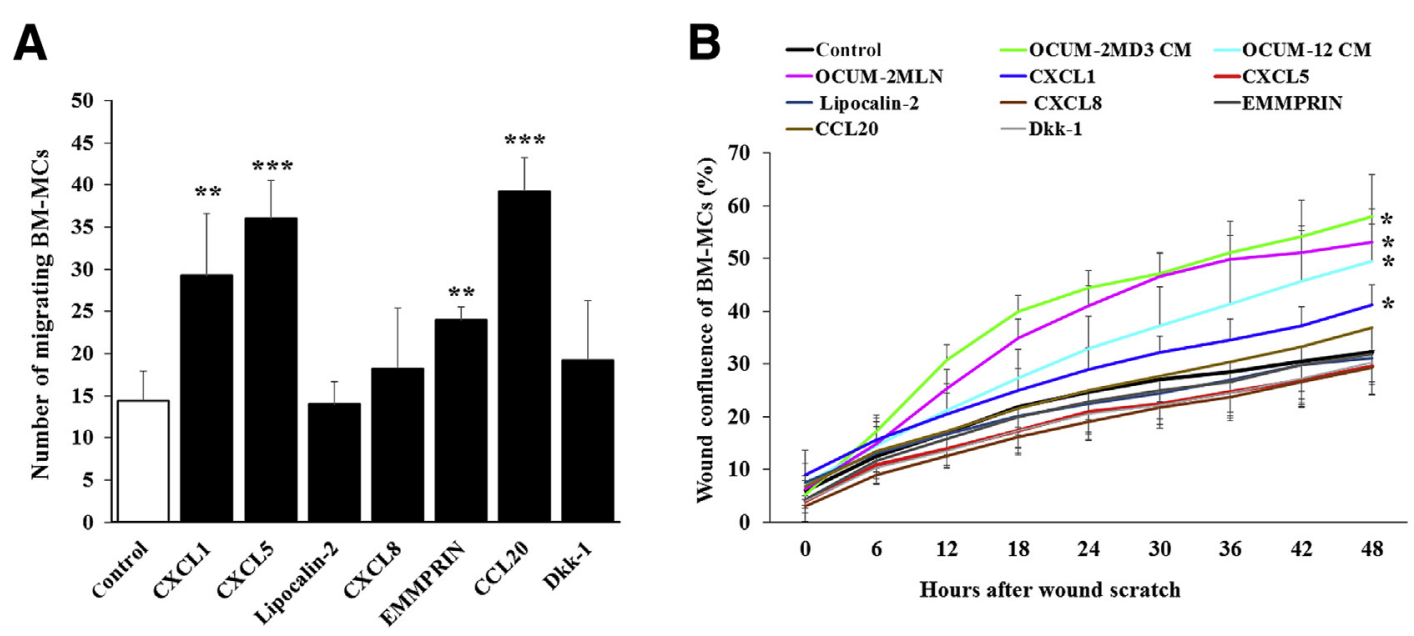

C

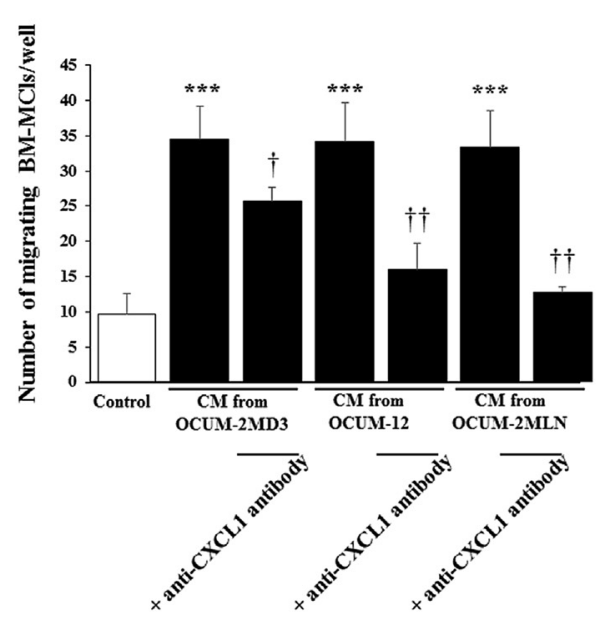

D

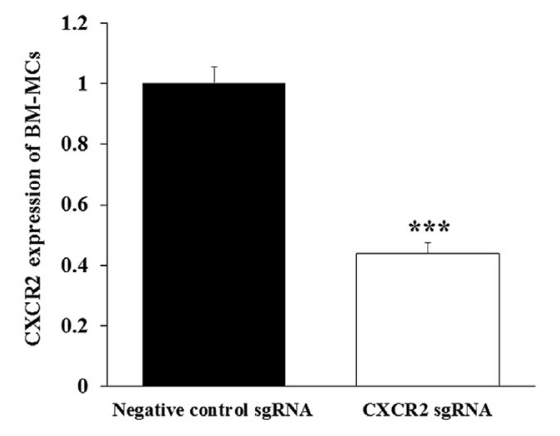

$\mathbf{E}$

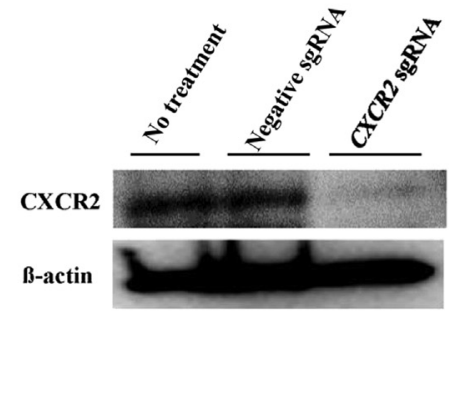

$\mathbf{F}$

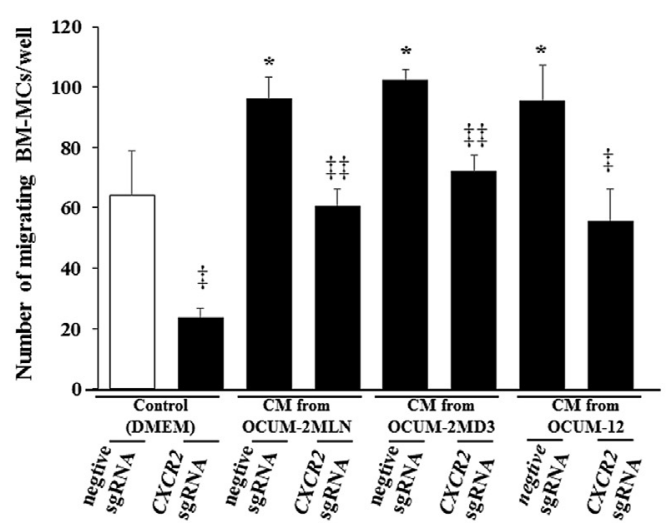

G

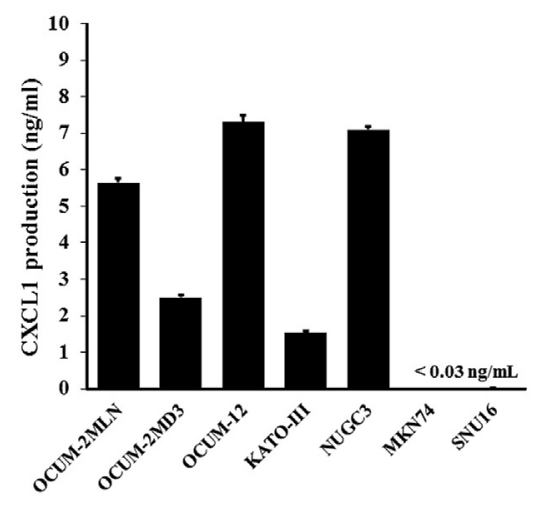

Figure 3 Determination of BM-MC migration-stimulating cytokines from cancer cells. A: Chemotaxis assay of BM-MCs with seven cytokines specifically detected in DGC cell lines. B: Wound-healing assay with cultured mediums from DGC cell lines and above seven cytokines. The mean of eight fields was calculated as the sample value. C: Effect of anti-CXCL1 antibody on the migration-stimulating activity of DGC cells in BM-MCs. D and E: Transfection of CXCR2 single guide RNA (sgRNA) by CRISPR/Cas9-mediated genome editing successfully decreased the expression of chemokine (C-X-C motif) receptor (CXCR) 2 mRNA and protein of BM-MCs. F: Effect of CXCR2 sgRNA transfection for BM-MCs on the migration-stimulating activity of scirrhous-type cancer cells. G: CXCL1 production in four DGC cell lines and two non-DGC cell lines. More than $1 \mathrm{ng} / \mathrm{mL}$ of CXCL1 was expressed in all DGC cell lines, not in non-DGC cell lines. $n=4$ (A, C, and $\mathbf{F}) ; n=3(\mathbf{B}, \mathbf{D}$, and $\mathbf{G}) .{ }^{*} P<0.05$, ${ }^{*}{ }^{*} P<0.01$, and ${ }^{*} * * P<0.001$ versus control; ${ }^{\dagger} P<0.05$, ${ }^{\dagger \dagger} P<0.01$ versus without CXCL1 antibody; ${ }^{\ddagger} P<0.05,{ }^{\sharp \ddagger} P<0.01$ versus with negative sgRNA. CCL, chemokine (C-C motif) ligand; DMEM, Dulbecco's modified Eagle's medium. 
A
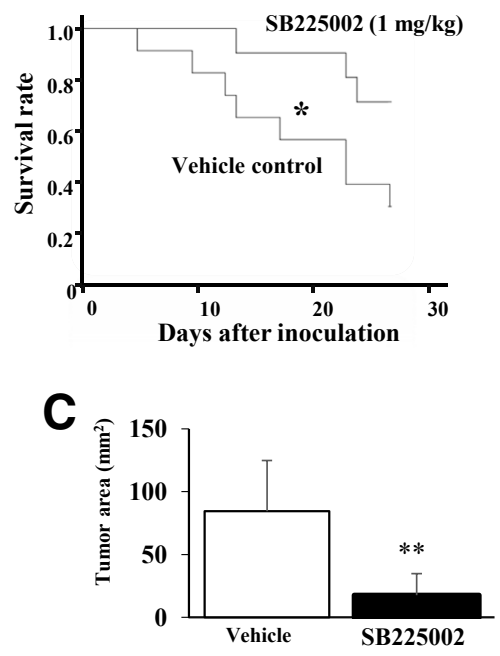

B

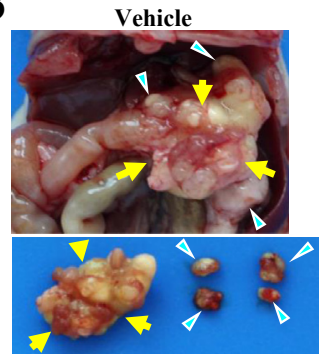

$\mathrm{SB225002}(1 \mathrm{mg} / \mathrm{kg})$

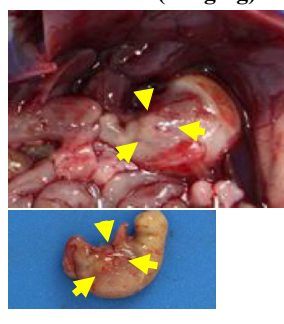

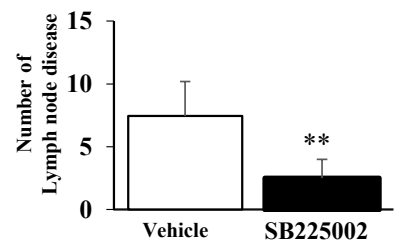

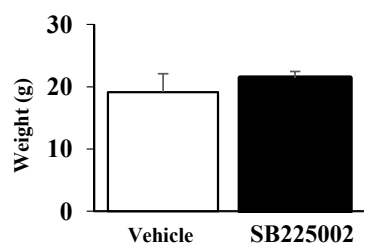

D

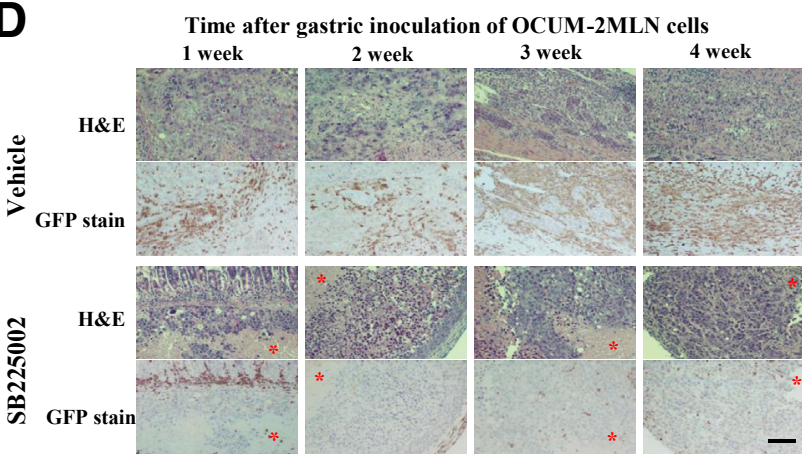

E
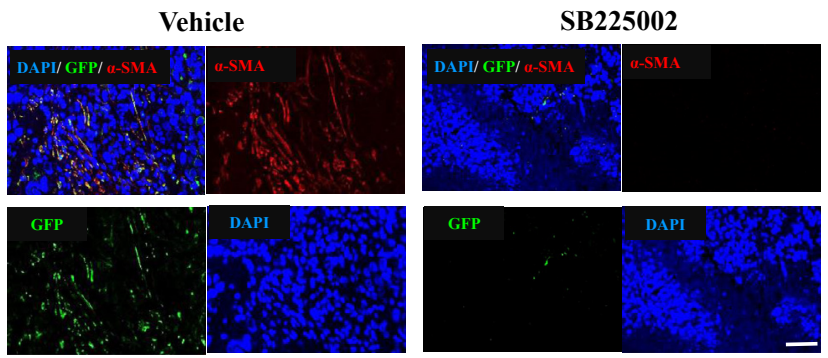

Figure 4 Effect of a chemokine (C-X-C motif) receptor (CXCR) 2 inhibitor, SB225002, on scirrhous gastric tumor in vivo. A: Survival of mice. The KaplanMeier survival curve indicates that the survival rate of mice injected SB225002 $(1 \mathrm{mg} / \mathrm{kg})$ was significantly $(P=0.039)$ better than that of control mice. B: Macroscopic image of gastric tumor. The gastric tumor of administered group was apparently smaller and the number of metastatic lymph nodes was lower than that of control group. Arrows indicate orthotopic tumor; arrowheads, lymph node metastasis. C: Effect of a CXCR2 inhibitor, SB225002, on tumor growth and lymph node metastasis. The tumor area and the number of metastatic lymph nodes in mice receiving SB225002 (1 mg/kg per day) were significantly lower than those of the vehicle control. D: The time course of gastric tumors after the inoculation and administration of a CXCR2 inhibitor. SB225002 administration decreased GFP-positive BM-MCs and increased necrotic lesions (red asterisks) in the tumor. E: Immunofluorescence microscopy. SB225002 dramatically decreased GFP-positive and $\alpha$-SMA-positive BM-derived myofibroblasts at 4 weeks after inoculation. ${ }^{*} P<0.05,{ }^{* *} P<0.01$. Scale bar $=50 \mu \mathrm{m}(\mathbf{D}$ and $\mathbf{E})$. $\mathrm{H} \& \mathrm{E}$, hematoxylin and eosin.

and 1.74 (Supplemental Figure S6A), the CXCR2 inhibitor did not affect the proliferative activities of gastric cancer cells and BM-MCs in our examinations (Supplemental Figure S6B). Lymphatic vessel endothelial hyaluronan receptor-1 staining indicated that tumor in lymphatic vessels showed medullary growth of cancer cells with scanty stromal cells. The tumors invaded the lymphatic vessel and did not show necrosis lesion in either the vehicle tumors or the treatment tumors, whereas frequent necrosis was evident in the primary tumors with SB225002 treatment (Figure 5B).

\section{Discussion}

The aim of the present investigation was to clarify the mechanisms responsible for tumor-homing BM-MCs to contribute a novel therapy for DGC. In this study, in vivo gastric tumors generated by OCUM-2MLN cells showed extensive stromal cells with poorly differentiated adenocarcinoma cells and lymph node metastasis, which resembled human DGC, as previously reported. ${ }^{17,29}$ This orthotopic model could contribute to the elucidation of disease progression in situ and the development of therapy in DGC..$^{30-32}$ Our mouse model using GFP bone marrow transplantation confirmed that bone marrow cells are present in the stroma of DGC. We demonstrated that BM-MCs scattered and specifically localized to the tumor nest at several days after inoculation. BM-MCs migrated into gastric tumor nest as cancer stroma, including $\alpha$-SMA-positive CAFs, F4/80-positive macrophages, and CD11bpositive leukocytes. Immunofluorescence microscopy found that most of GFP-positive BM-MCs existed as $\alpha$ SMA-positive myofibroblasts in tumor microenvironment, suggesting that most CAFs originate from BM-MCs. A 
A
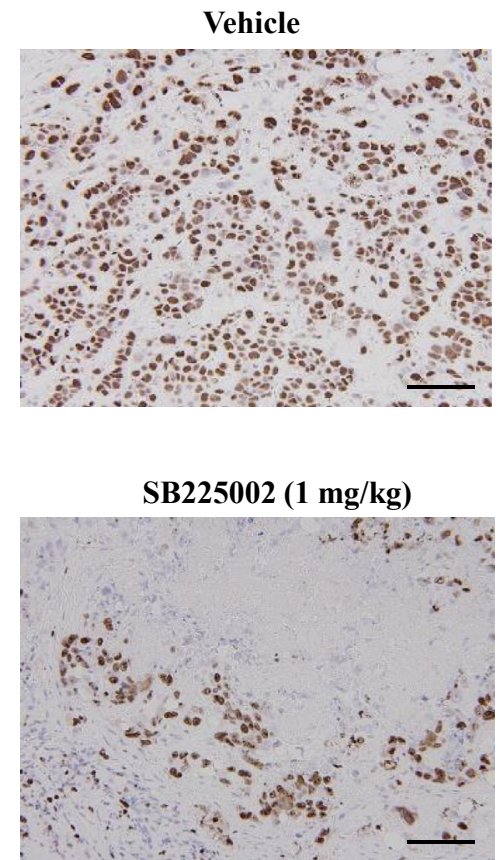

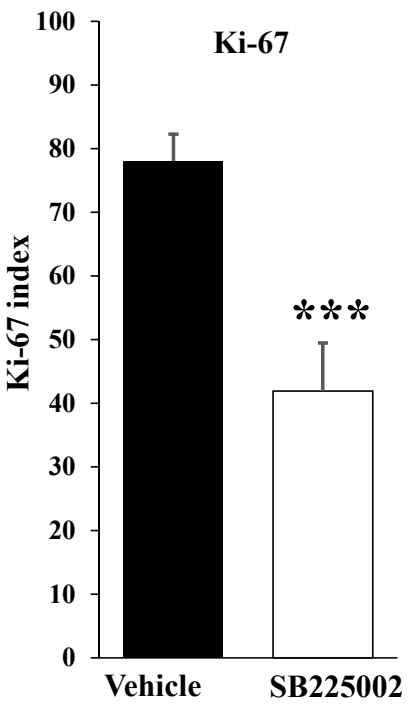

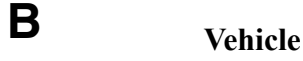

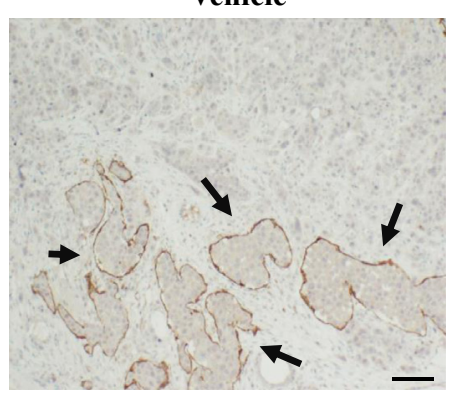

SB225002

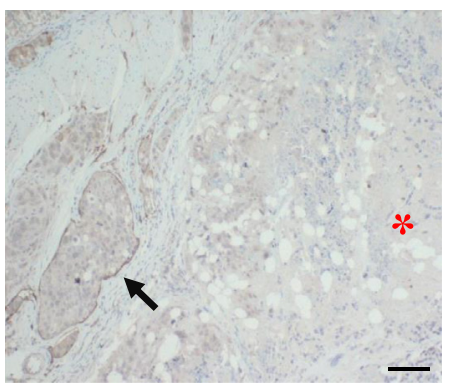

Figure 5 Ki-67 and lymphatic vessel endothelial hyaluronan receptor-1 staining of scirrhous gastric tumor. A: Expression levels of Ki-67 in cancer cells of the mice by SB225002 were significantly lower than those in the vehicle mice. Six randomly chosen fields were counted for each assay, and the mean of six fields was calculated as the sample value. B: Tumors invaded lymphatic vessel (arrows) and grew medulla with few stromal cells. SB225002 treatment did not increase necrotic lesions of tumors in lymphatic vessels, whereas frequent necrosis (red asterisk) was evident in the primary tumors. $n=4$ (A). $* * * P<0.001$. Scale bar $=100 \mu \mathrm{m}(\mathbf{A}$ and $\mathbf{B})$.

secreted paracrine factor(s) from DGC cells may recruit BM-MCs into tumor and differentiate into $\alpha$-SMA-positive myofibroblasts because BM-MCs have the potential to be fibroblasts. These results might indicate that abundant stromal cells in DGC were mainly consistent with BM-MCs, which differentiated into $\alpha$-SMA-positive myofibroblasts. ${ }^{33}$ We previously reported that CAFs, particularly myofibroblasts, play an important role in the development of DGC. ${ }^{14,23}$ Ishii et $a^{26}$ also indicated that bone marrow-derived myofibroblasts become a major component of cancer-induced stromal cells in the later stage of tumor development. Therefore, BM-MCs appear to play an important role for the development of gastric cancer as CAFs in tumor microenvironment.

The gastric tumors produced by DGC cell lines, OCUM2MD3 cells, and OCUM-12 cells also showed histologically infiltrative growth with extensive stromal cells. In contrast, gastric tumors produced by non-DGC cell lines, SNU16 cells, and MKN74 cells showed medullary growth with sparse stromal cells. These findings suggested that DGC cells may secrete a factor(s) that recruits bone marrow cells into the tumor microenvironment, but not non-DGC cells. Although it has been reported that BM-MCs contribute to tumor progression, ${ }^{34,35}$ the mechanism responsible for the recruitment of BM-MCs in DGC has not been clarified. Subsequently, using these DGC models, we identified the key signal associated with recruitment of BM-MCs, as follows. We examined the chemotaxis-stimulating factor in
$\mathrm{CM}$ from DGC cells using BM-MCs in vitro. CM from DGC cells significantly increased twofold or threefold the migratory ability of BM-MCs but not non-DGC cells, suggesting that BM-MCs were preferentially recruited by a factor(s) from DGC cells. To identify the molecules enhancing the homing capability of BM-MCs, we screened a total of 102 chemokines using the protein array and compared the protein production level between DGC cells and non-DGC cells. The protein array indicated that 7 of 102 chemokines, CXCL1, CXCL5, lipocalin-2, CXCL8, Dkk1, CCL20, and EMMPRIN, were expressed in DGC but not in the non-DGC cell lines, MKN74 and SNU16. Among these seven factors, only CXCL1 significantly stimulated both the invasion activity and mobility of BM-MCs, but the other six factors did not. The migration-stimulating activity of DGC cells was significantly decreased by an anti-CXCL1 neutralizing antibody. Moreover, the genetic knockdown of CXCR2, a receptor for CXCL1, by CXCR2 single guide RNA transfection significantly decreased the migration activity of BM-MCs. These findings suggested that DGC cells stimulated the tumor-homing capability of BM-MCs in a paracrine manner via the CXCL1/CXCR2 axis. Taken together, CXCL1 was highly expressed in CM of other types of solid cancers, such as undifferentiated pancreatic cancer cells, SW1990 and MiaPaCa2, and triple-negative breast cancer cells, MDA231 (Supplemental Figure S7A). These pancreatic and breast cancer cell lines also stimulated the migration capacity of BM-MCs (Supplemental 


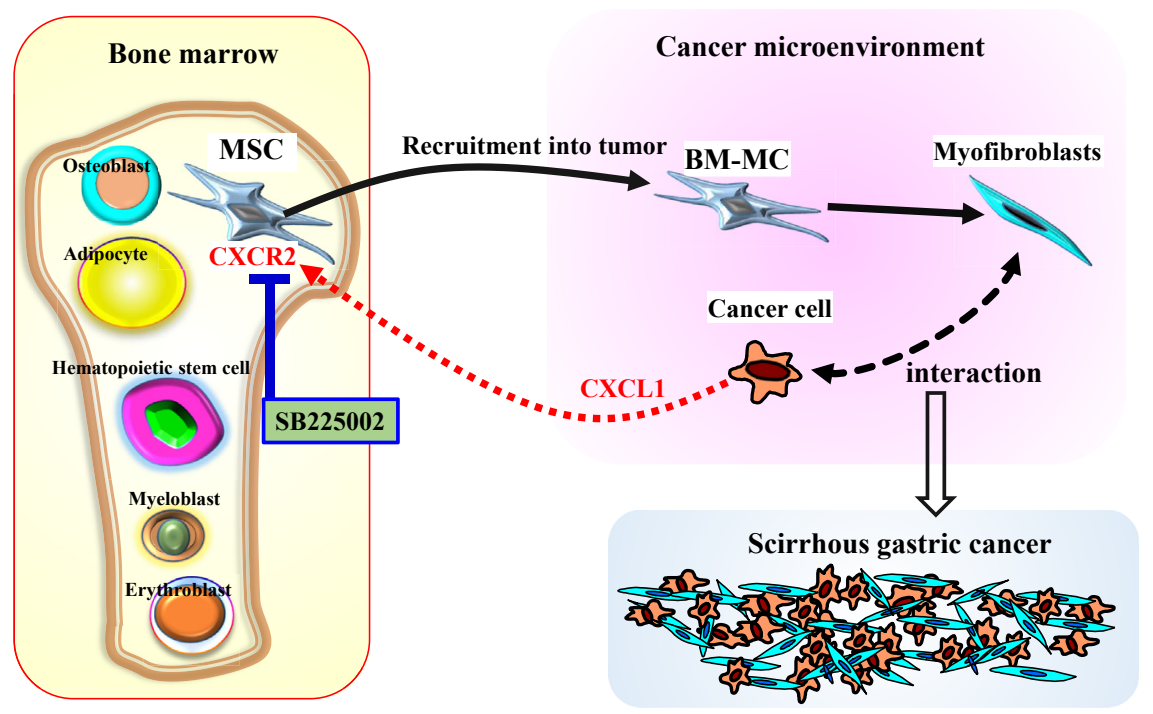

Figure 6 Schema of the mechanisms responsible for the recruitment of BM-MCs into scirrhoustype gastric cancer. CXCL1 secreted from DGC recruits $B M-M C s$ into the tumor microenvironment. Homing of BM-MCs differentiated into myofibroblasts, which stimulates the progression of DGC. Myofibroblasts and cancer cells could mutually increase each other's proliferation, thus resulting in highly malignant DGC. SB225002, a chemokine (C-X-C motif) receptor (CXCR) 2 inhibitor, reduced BM-MCs' recruitment into cancer locus and subsequently decreased myofibroblasts as cancerassociated fibroblasts. MSC, mesenchymal stem cell.

Figure S7, B and C). Although several studies revealed that CXCR2 expression in cancer was associated with cancer development in lung adenocarcinoma, ${ }^{36}$ colorectal tumorigenesis, ${ }^{37}$ and pancreatic cancer, ${ }^{28}$ there has been no study demonstrating the relationship between cancer cells and BM-MCs in the CXCL1-CXCR2 axis. Some types of solid cancers might recruit BM-MCs into the tumor microenvironment via the CXCL1-CXCR2 signaling. Although it has been reported that stromal cell-derived factor 1 (CXCL12), ${ }^{34,38,39}$ CXCL8 (IL-8), ${ }^{40}$ CXCL5, CCL2, ${ }^{41}$ and vascular endothelial growth factor ${ }^{42}$ recruited BM-MCs into the tumor stroma, these factors did not affect the migration activities of BM-MCs by chemotaxis assay and woundhealing assay in this study. Connective tissue growth factor (CTGF) was also reported to be associated with tumorstromal interaction $^{28}$; however, our RT-PCR data indicated that CTGF might not be associated with the tumor homing of BM-MCs in gastric cancer because of low expression of $C T G F$ in cancer cells (Supplemental Figure S8). As seen in the figure, CTGF mRNA was scarcely expressed in gastric cancer cell lines (within the range from 1 of OCUM-2M to 203 of NUGC-3) in comparison with fibroblast cell lines (within the range from 1233 of OCUM-2M to 9383 of NUGC-3).

Because our study indicated that DGC cells may acquire high malignant potential by the recruitment of BM-MCs into tumor microenvironment as CAFs, the inhibition of the recruitment of BM-MCs into cancer locus may be a promising therapy for the treatment of DGC. Our gastric tumor model revealed that most stromal cells in cancer lesions were the migrating BM-MCs at 4 weeks after inoculation. Then, an in vivo experiment was mainly evaluated 4 weeks after inoculation. Administration of SB225002, a selective CXCR2 antagonist, demonstrated the effective suppression of tumor growth and lymph node metastasis of DGC in mice, whereas SB225002 did not affect the proliferation of DGC cells in vitro. Tumor histology showed that SB225002 reduced tumor stromal cells and increased necrotic lesions. Because BM-MCs were scanty in SB225002-treated tumors, CXCR2 inhibitor decreased BM-MCs' migration and subsequently increased necrosis of cancer cells. GFP-positive cells gathered around the inoculated tumor at 1 week in the SB225002 group. GFP-positive cells were found around the tumor but not in the tumor in the SB225002 group, whereas GFP-positive cells were found in the tumor in the vehicle group. BM-MCs could not infiltrate into gastric tumor in the SB225002 group. SB225002 might inhibit not only the recruitment of BM-MCs into stomach but also the infiltration into the tumor microenvironment around tumor. Because stromal cells were few in lymphatic vessel, SB225002 might not affect the growth of cancer cells that invaded into the lymphatic vessels. These results suggested that the CXCR2 inhibitor suppressed BM-MC migration capacity, subsequently resulting in the reduction of tumor size by inhibiting the interaction between DGC cells and myofibroblasts. Ijichi et $\mathrm{al}^{28}$ also reported that CXCR2 genetic knockdown in the stromal fibroblasts had a strong impact on pancreas tumor growth. The molecular controls of tumor-induced fibroblasts via the CXCL1-CXCR2 signaling system may be useful for the treatment of stroma-enriched cancer.

In conclusion, DGC recruits BM-MCs into tumor microenvironment via CXCL1-CXCR2 signaling. CXCR2 inhibitor might decrease the size of DGC and prolonged the survival of DGC mice by inhibiting tumor-homing of BMMCs. CXCR2 signal is a promising therapeutic target for patients with DGC (Figure 6).

\section{Acknowledgments}

We thank Maiko Nagai (Osaka City University Graduate School of Medicine) for technical assistance. 
H.Ka. and M.Y. designed and performed the experiments and cowrote the manuscript; K.K., G.M., H.Ki., T.F., and T.H. contributed to the in vitro experiments; H.N., T.N., and M.H. collected the bone marrow specimen; K.H. and M.O. suggested and codesigned the study and cowrote the manuscript.

\section{Supplemental Data}

Supplemental material for this article can be found at http://dx.doi.org/10.1016/j.ajpath.2016.07.024.

\section{References}

1. Noda S, Yashiro M, Toyokawa T, Morimoto J, Shinto O, Muguruma K, Sawada T, Hirakawa K: Borrmann's macroscopic criteria and $\mathrm{p}-\mathrm{Smad} 2$ expression are useful predictive prognostic markers for cytology-positive gastric cancer patients without overt peritoneal metastasis. Ann Surg Oncol 2011, 18:3718-3725

2. Kim DY, Kim HR, Kim YJ, Kim S: Clinicopathological features of patients with Borrmann type IV gastric carcinoma. ANZ J Surg 2002, 72:739-742

3. Wadhwa R, Song S, Lee JS, Yao Y, Wei Q, Ajani JA: Gastric cancer: molecular and clinical dimensions. Nat Rev Clin Oncol 2013, 10 : 643-655

4. Liu Y, Yoshimura K, Yamaguchi N, Shinmura K, Yokota J, Katai H: Causation of Borrmann type 4 gastric cancer: heritable factors or environmental factors? Gastric Cancer 2003, 6:17-23

5. Chen CY, Wu CW, Lo SS, Hsieh MC, Lui WY, Shen KH: Peritoneal carcinomatosis and lymph node metastasis are prognostic indicators in patients with Borrmann type IV gastric carcinoma. Hepatogastroenterology 2002, 49:874-877

6. Willett CG: Results of radiation therapy in gastric cancer. Semin Radiat Oncol 2002, 12:170-175

7. Samel S, Singal A, Becker H, Post S: Problems with intraoperative hyperthermic peritoneal chemotherapy for advanced gastric cancer. Eur J Surg Oncol 2000, 26:222-226

8. Furukawa H, Iwanaga $\mathrm{T}$, Hiratsuka $\mathrm{M}$, Imaoka S, Ishikawa $\mathrm{O}$, Kabuto T, Sasaki Y, Kameyama M, Ohigashi H, Nakamori S: Gastric cancer in young adults: growth accelerating effect of pregnancy and delivery. J Surg Oncol 1994, 55:3-6

9. Ikeguchi M, Miyake T, Matsunaga T, Yamamoto M, Fukumoto Y, Yamada Y, Fukuda K, Saito H, Tatebe S, Tsujitani S: Recent results of therapy for scirrhous gastric cancer. Surg Today 2009, 39: 290-294

10. Fuyuhiro Y, Yashiro M, Noda S, Kashiwagi S, Matsuoka J, Doi Y, Kato Y, Muguruma K, Sawada T, Hirakawa K: Myofibroblasts are associated with the progression of scirrhous gastric carcinoma. Exp Ther Med 2010, 1:547-551

11. Kalluri R, Zeisberg M: Fibroblasts in cancer. Nat Rev Cancer 2006, 6: 392-401

12. Otsuji E, Kuriu Y, Okamoto K, Ochiai T, Ichikawa D, Hagiwara A, Yamagishi H: Outcome of surgical treatment for patients with scirrhous carcinoma of the stomach. Am J Surg 2004, 188:327-332

13. Fuchs CS, Mayer RJ: Gastric carcinoma. N Engl J Med 1995, 333: $32-41$

14. Yashiro M, Chung YS, Sowa M: Role of orthotopic fibroblasts in the development of scirrhous gastric carcinoma. Jpn J Cancer Res 1994 $85: 883-886$

15. Kasashima H, Yashiro M, Nakamae H, Masuda G, Kinoshita H, Morisaki T, Fukuoka T, Hasegawa T, Sakurai K, Toyokawa T, Kubo N, Tanaka H, Muguruma K, Ohira M, Nakane T, Hino M,
Hirakawa K: Bone marrow-derived stromal cells are associated with gastric cancer progression. Br J Cancer 2015, 113:443-452

16. Yashiro M, Chung YS, Nishimura S, Inoue T, Sowa M: Establishment of two new scirrhous gastric cancer cell lines: analysis of factors associated with disseminated metastasis. $\mathrm{Br}$ J Cancer 1995, 72: $1200-1210$

17. Fujihara T, Sawada T, Hirakawa K, Chung YS, Yashiro M, Inoue T, Sowa M: Establishment of lymph node metastatic model for human gastric cancer in nude mice and analysis of factors associated with metastasis. Clin Exp Metastasis 1998, 16:389-398

18. Yashiro M, Chung YS, Nishimura S, Inoue T, Sowa M: Peritoneal metastatic model for human scirrhous gastric carcinoma in nude mice. Clin Exp Metastasis 1996, 14:43-54

19. Kato Y, Yashiro M, Noda S, Tendo M, Kashiwagi S, Doi Y, Nishii T, Matsuoka J, Fuyuhiro Y, Shinto O, Sawada T, Ohira M, Hirakawa K: Establishment and characterization of a new hypoxia-resistant cancer cell line, OCUM-12/Hypo, derived from a scirrhous gastric carcinoma. Br J Cancer 2010, 102:898-907

20. Sekiguchi M, Sakakibara K, Fujii G: Establishment of cultured cell lines derived from a human gastric carcinoma. Jpn J Exp Med 1978, 48:61-68

21. Nomura H, Nishimori H, Yasoshima T, Hata F, Sogahata K, Tanaka H, Nakajima F, Ikeda S, Kamiguchi K, Isomura H, Sato N, Denno R, Hirata K: A novel experimental mouse model of peritoneal dissemination of human gastric cancer cells: analysis of the mechanism of peritoneal dissemination using cDNA macroarrays. Jpn J Cancer Res 2001, 92:748-754

22. Motoyama T, Hojo H, Watanabe H: Comparison of seven cell lines derived from human gastric carcinomas. Acta Pathol Jpn 1986, 36 : $65-83$

23. Fuyuhiro Y, Yashiro M, Noda S, Matsuoka J, Hasegawa T, Kato Y, Sawada T, Hirakawa K: Cancer-associated orthotopic myofibroblasts stimulates the motility of gastric carcinoma cells. Cancer Sci 2012, 103:797-805

24. Caiado F, Carvalho T, Rosa I, Remedio L, Costa A, Matos J, Heissig B, Yagita H, Hattori K, da Silva JP, Fidalgo P, Pereira AD, Dias S: Bone marrow-derived $\mathrm{CD} 11 \mathrm{~b}+\mathrm{Jagged} 2+$ cells promote epithelial-to-mesenchymal transition and metastasization in colorectal cancer. Cancer Res 2013, 73:4233-4246

25. Karnoub AE, Dash AB, Vo AP, Sullivan A, Brooks MW, Bell GW, Richardson AL, Polyak K, Tubo R, Weinberg RA: Mesenchymal stem cells within tumour stroma promote breast cancer metastasis. Nature 2007, 449:557-563

26. Ishii G, Sangai T, Oda T, Aoyagi Y, Hasebe T, Kanomata N, Endoh Y, Okumura C, Okuhara Y, Magae J, Emura M, Ochiya T, Ochiai A: Bone-marrow-derived myofibroblasts contribute to the cancer-induced stromal reaction. Biochem Biophys Res Commun 2003, 309:232-240

27. Kasashima H, Yashiro M, Kinoshita H, Fukuoka T, Morisaki T, Masuda G, Sakurai K, Kubo N, Ohira M, Hirakawa K: Lysyl oxidase is associated with the epithelial-mesenchymal transition of gastric cancer cells in hypoxia. Gastric Cancer 2016, 19:431-442

28. Ijichi H, Chytil A, Gorska AE, Aakre ME, Bierie B, Tada M, Mohri D, Miyabayashi K, Asaoka Y, Maeda S, Ikenoue T, Tateishi K, Wright CV, Koike K, Omata M, Moses HL: Inhibiting Cxcr2 disrupts tumor-stromal interactions and improves survival in a mouse model of pancreatic ductal adenocarcinoma. J Clin Invest 2011, 121:4106-4117

29. Takemura S, Yashiro M, Sunami T, Tendo M, Hirakawa K: Novel models for human scirrhous gastric carcinoma in vivo. Cancer Sci 2004, 95:893-900

30. Yashiro M, Hirakawa K: Cancer-stromal interactions in scirrhous gastric carcinoma. Cancer Microenviron 2010, 3:127-135

31. Yashiro M, Shinto O, Nakamura K, Tendo M, Matsuoka T, Matsuzaki T, Kaizaki R, Ohira M, Miwa A, Hirakawa K: Effects of VEGFR-3 phosphorylation inhibitor on lymph node metastasis in an orthotopic diffuse-type gastric carcinoma model. Br J Cancer 2009, 101:1100-1106 
32. Yashiro M, Shinto O, Nakamura K, Tendo M, Matsuoka T, Matsuzaki T, Kaizaki R, Miwa A, Hirakawa K: Synergistic antitumor effects of FGFR2 inhibitor with 5-fluorouracil on scirrhous gastric carcinoma. Int J Cancer 2010, 126:1004-1016

33. Mishra PJ, Mishra PJ, Humeniuk R, Medina DJ, Alexe G, Mesirov JP, Ganesan S, Glod JW, Banerjee D: Carcinoma-associated fibroblast-like differentiation of human mesenchymal stem cells. Cancer Res 2008, 68:4331-4339

34. Bergfeld SA, Blavier L, DeClerck YA: Bone marrow-derived mesenchymal stromal cells promote survival and drug resistance in tumor cells. Mol Cancer Ther 2014, 13:962-975

35. Kidd S, Spaeth E, Watson K, Burks J, Lu H, Klopp A, Andreeff M, Marini FC: Origins of the tumor microenvironment: quantitative assessment of adipose-derived and bone marrow-derived stroma. PLoS One 2012, 7:e30563

36. Saintigny P, Massarelli E, Lin S, Ahn YH, Chen Y, Goswami S, Erez B, O'Reilly MS, Liu D, Lee JJ, Zhang L, Ping Y, Behrens C, Solis Soto LM, Heymach JV, Kim ES, Herbst RS, Lippman SM, Wistuba II, Hong WK, Kurie JM, Koo JS: CXCR2 expression in tumor cells is a poor prognostic factor and promotes invasion and metastasis in lung adenocarcinoma. Cancer Res 2013, 73:571-582

37. Katoh H, Wang D, Daikoku T, Sun H, Dey SK, Dubois RN: CXCR2expressing myeloid-derived suppressor cells are essential to promote colitis-associated tumorigenesis. Cancer Cell 2013, 24:631-644
38. Quante M, Tu SP, Tomita H, Gonda T, Wang SS, Takashi S, Baik GH, Shibata W, Diprete B, Betz KS, Friedman R, Varro A, Tycko B, Wang TC: Bone marrow-derived myofibroblasts contribute to the mesenchymal stem cell niche and promote tumor growth. Cancer Cell 2011, 19:257-272

39. Shibata W, Ariyama H, Westphalen CB, Worthley DL, Muthupalani S, Asfaha S, Dubeykovskaya Z, Quante M, Fox JG, Wang TC: Stromal cell-derived factor-1 overexpression induces gastric dysplasia through expansion of stromal myofibroblasts and epithelial progenitors. Gut 2013, 62:192-200

40. Birnbaum T, Roider J, Schankin CJ, Padovan CS, Schichor C, Goldbrunner R, Straube A: Malignant gliomas actively recruit bone marrow stromal cells by secreting angiogenic cytokines. J Neurooncol 2007, 83:241-247

41. Dwyer RM, Potter-Beirne SM, Harrington KA, Lowery AJ, Hennessy E, Murphy JM, Barry FP, O’Brien T, Kerin MJ: Monocyte chemotactic protein-1 secreted by primary breast tumors stimulates migration of mesenchymal stem cells. Clin Cancer Res 2007, 13: $5020-5027$

42. Schichor C, Birnbaum T, Etminan N, Schnell O, Grau S, Miebach S, Aboody K, Padovan C, Straube A, Tonn JC, Goldbrunner R: Vascular endothelial growth factor A contributes to glioma-induced migration of human marrow stromal cells (hMSC). Exp Neurol 2006, 199:301-310 